\title{
A socio-cultural explanation of black entrepreneurship in South Africa
}

\author{
M.J. Co* \\ Division of Management, School of Economics and Management \\ University of Natal, Durban 4041, Republic of South Africa \\ com@nu.ac.za
}

Received July 2003

\begin{abstract}
This article attempts to provide the reader an analysis of why entrepreneurship levels among indigenous Africans are low by specifically using socio-cultural theories. Traditional views of entrepreneurship have emphasised psychological and economic models. Although these views explain entrepreneurial activity, neither can explain it holistically. The sociocultural theoretical approach takes into account differences among societies and cultures in explaining entrepreneurial activity. The choice of this theoretical perspective and the specific theories highlighted is rationalised in the first section of this paper. The paper covers five main socio-cultural theories namely: Weber's Protestant ethic, Hagen's withdrawal of status, social mobility, marginality and role models. A model is then conceptualised, incorporating the different variables affecting entrepreneurship as identified from the above-mentioned theories and using the Black South Africans as a case illustration.
\end{abstract}

*To whom all correspondence should be addressed.

\section{Introduction}

Several authors (Begley, Tan, Larasati, Rab, Zamora \& Nanayakkara, 1997) have stressed the potential importance of socio-cultural variables in explaining variations in entrepreneurship and economic development. According to Wilken (1979:2), entrepreneurship has been regarded by many as one, perhaps the most, significant causal factor in the process of economic growth and development. Hence, differences in entrepreneurship among societies are believed to account for their differential rates of growth and development.

Shapero and Sokol (1982) said that the social and cultural factors that enter into the formation of entrepreneurial events are most felt through the formation of individual value systems. More specifically, in a social system that places a high value on the formation of new ventures, more individuals will choose the path in times of transition.

This article attempts to provide the reader an analysis of why entrepreneurship levels among indigenous Africans are low by specifically using the socio-cultural approach. The first part of the article will contain a discussion on selected socio-cultural theories that try to explain the emergence of entrepreneurial activity and the corresponding criticisms each has received. The second section presents a conceptual model that will incorporate the various factors identified in the socio-cultural theories discussed in section one. The socio-cultural conditions that the Black South Africans experience will be used to illustrate the formulated conceptual model. The last section will contain the summary, conclusion and some suggested topics for further research.
The discussion will concentrate on socio-cultural explanations of entrepreneurship activity only. Traditional views of entrepreneurship have emphasised psychological and economic models. Personality based theories posit that people's special personality traits make them prone to behaving and succeeding as entrepreneurs. The list of traits is endless but includes internal locus of control, low aversion to risk taking, aggressiveness, ambition, marginality, and high need for achievement. Economic models on the other hand, assume that with clear vision of one's goals and all the required information, a person makes a decision to enter self-employment. The motivated person scans the market and chooses a niche that will maximise his or her returns on assets invested in the business. Although both views explain entrepreneurship activity, neither can explain it holistically. It is important to view entrepreneurship activity in the context of the socio-cultural environment - the norms, values, structures in society, taking into account regional and cultural differences.

Five theories will be discussed in this paper: for the macro perspective-Max Weber's Protestant Ethic, Everett Hagen's Withdrawal of Social Status, and social mobility; for micro explanations, marginality and the effect of role models will be discussed. The author believes that these five theories use explanatory factors that are so different from each other that they cover the most important areas in the socio-cultural aspect. The researcher also feels that these five theories form the basic core of the socio-cultural approach and that whatever theories formulated in the future will be derived from them. 


\section{Socio-cultural explanations}

This section will be divided into two parts - the macro and micro explanations. Macro explanations deal with society, its structure, culture, and institutions and their effects in encouraging entrepreneurial activities. The micro explanations on the other hand, focus on the experience of the individual entrepreneur and the effects of these experiences on the individual's motivation to be an entrepreneur.

\section{Macro level explanations}

\section{Weber's protestant ethic}

Weber (1958:97) was interested in the influence of the psychological sanctions which originated from religious belief and the practice of religion to the practical conduct of an individual. After careful study, Weber came to the belief that the Protestant ethic broke the hold of tradition while it encouraged men to apply themselves rationally to their work. The drive to accumulate wealth without an interest in worldly pleasures it can purchase is linked to moral selfdiscipline. The Calvinist doctrine of predestination forces people to assume they have been chosen. The performance of good works in worldly activity became accepted as the way of demonstrating salvation. It was believed by followers of Calvin that one could not do good works or perform acts of faith to assure your place in heaven. You were either among the 'elect' (in which case you were in) or you were not. However, wealth was taken as a sign (by you and your neighbours) that you were one of God's elect, thereby providing encouragement for people to acquire wealth. The Protestant ethic therefore provided religious sanctions that fostered a spirit of rigorous discipline encouraging men to apply themselves rationally to acquire wealth. Wealth was sanctioned as long as it was not used to support a life of idle luxury or self-indulgence.

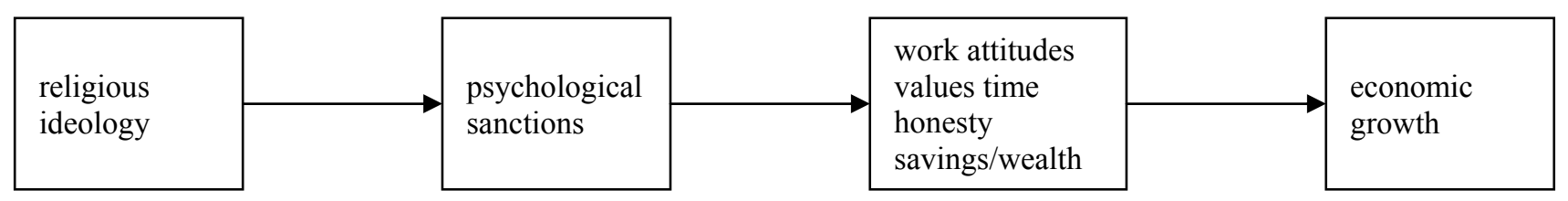

Figure 1: Diagram showing the relationship of variables in Weber's protestant ethic

In Weber's (1958:155-183) chapter on asceticism and the spirit of capitalism, he discusses the connection between the fundamental religious ideas of Protestantism and its maxims for everyday economic conduct.

First, he mentions that waste of time is the first and in principle the deadliest of sins. Because man's life is short and precious, loss of time through sociability, idle talk, luxury, even more sleep than necessary is worthy of absolute moral condemnation. Every hour lost is lost to labour for the glory of God.

Then he discusses labour, and the concept of working hard in ones calling. Wealth does not exempt anyone from working. For everyone without exception God's providence has prepared a calling, which he should profess and in which he should labour. The perseverance of the individual in the place and within the limits which God has assigned to him was a religious duty. This fixed calling provided ethical justification of the modern specialisation of labour.

Wealth according to Weber is bad ethically only when it is a temptation to idleness and sinful enjoyment of life, and its acquisition is bad only when it is the purpose of later living merrily and without care. This on the other hand encouraged people to save by not indulging in outward forms of luxury, which was condemned as idolatry of the flesh. These saving are now accumulated as capital, which can be returned to the economy resulting in economic development.
While Weber (1958:91) does not believe that the Protestant ethic was the only cause of the rise of capitalism, he believed it to be a powerful force in fostering its emergence. The main criticism against Weber is that it does not explain the emergence of entrepreneurship in non-Protestant societies. This explanation is only applicable to the North Atlantic community, but does little to explain events in other countries. (Shapero \& Sokol, 1982).

This author believes that even if Weber's theory does not holistically explain entrepreneurship behaviour, it has paved the way for people to consider socio-cultural variables in explaining the phenomenon. Because of this reason, it is still an important theory that merits mention in this paper.

\section{Hagen's withdrawal of status respect}

Everett Hagen's theory (1962: Chapters 9-12) of the genesis of entrepreneurship makes substantial use of social variables although the crux of his argument concerns the psychological changes, which result from certain social changes.

As the phrase that has been applied to his theory implies, Hagen believes that the initial condition leading to eventual entrepreneurial behaviour is the loss of status by a group or collectivity. This can occur in one of four ways: 


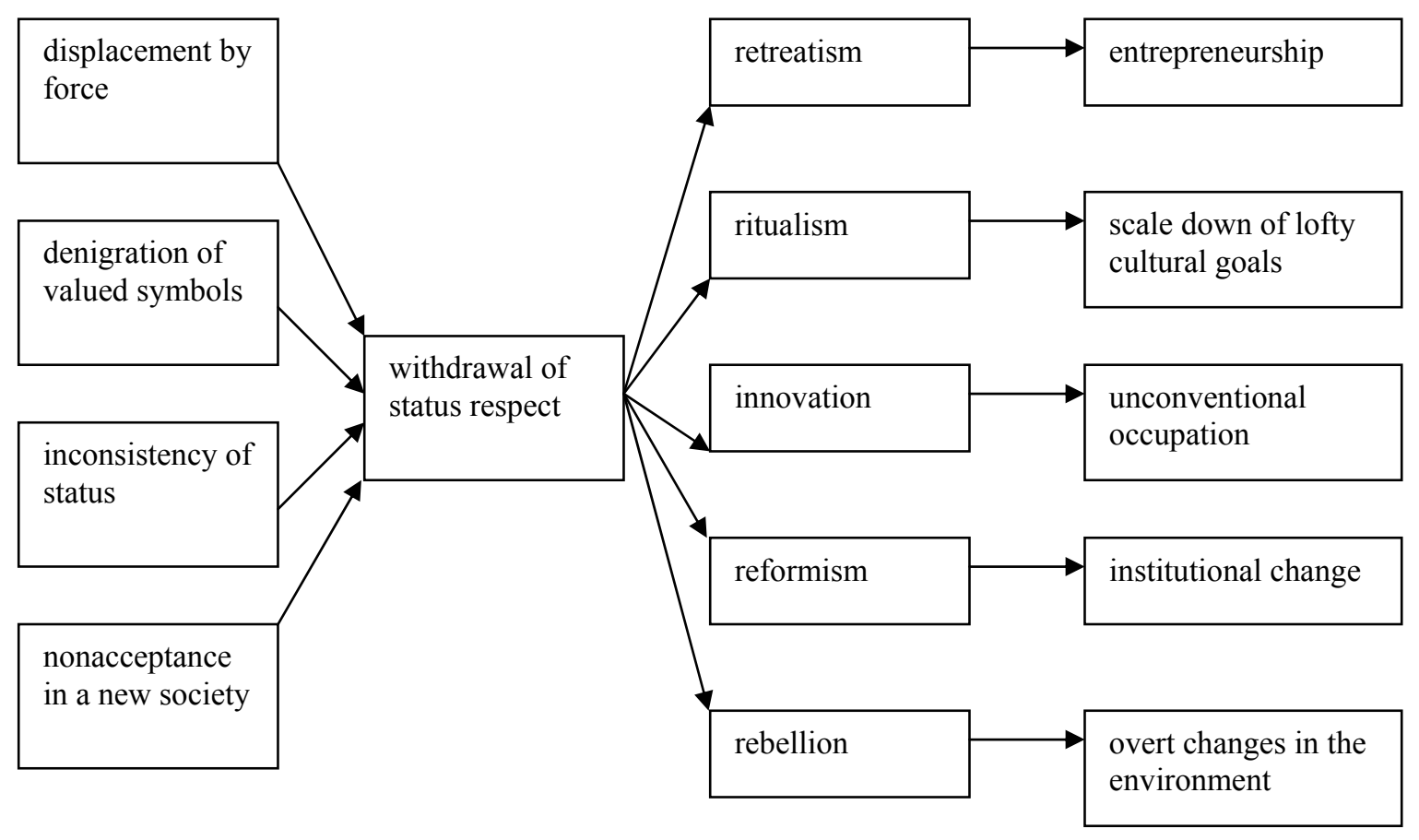

Figure 2: Diagram showing the relationship of variables in Hagen's withdrawal of status respect

(1) the group may be displaced by force - usually by physical force which causes a change in power structure.;

(2) it may have its valued symbols denigrated - when there is a change in the attitude of the superior group and prohibits some activity or relationship vital to the sense of status of a subordinate group. There may be manifestations of contempt, scorn or some other degree of psychological ostracism by a high prestige group to a subordinate group because of distaste for some element in the role of the subordinate group.;

(3) it may drift into a situation of status inconsistency when there is status displacement because of the development and long continuance of inconsistency between economic and other status relationships.; and

(4) it may not be accepted in a new society - migration of a group into a new society in which it does not have prestige, if they expect their position to be respected, tensions will rise causing social changes.

Hagen suggests that there are several possible reactions to this loss of group status: retreatism, ritualism, innovation, reformism, and rebellion. The most significant of these for entrepreneurship is retreatism, which is characterised by psychological repression of trauma associated with the status loss. The suppressed rage resulting from the loss of status ultimately results in a later generation in standards of achievement being held up by mothers within the group to their sons. If the sons' fathers are simultaneously weak or erratic, then the likelihood of the sons' becoming innovators is increased and entrepreneurship becomes a feasible outlet for such tendencies.
Hagen supplements this basic model with a number of variables. He regards relative social blockage as being crucial in determining the channel to which creative energies flow. Hence the personality changes resulting from the withdrawal of status respect in prior generations are not sufficient to produce entrepreneurship. He further notes that the state of knowledge available, the size of markets, the amount of savings available for investment, and attitudes toward manual labour will be significant. In other words, the opportunities present in the individual's situation will be an important factor in determining whether the psychological process yields entrepreneurship.

There are several criticisms of Hagen's theory:

(1) The most damaging among all the criticisms of Hagen's theory is the allegation that his theory is post hoc, that he has discovered instances of the withdrawal of status respect by looking first at situations in which economic growth occurred and by looking for status losses that may have preceded that growth (Kilby, 1971).

(2) The second major criticism has centered on the long period of time-as much as five or more generationsrequired for the withdrawal of status respect to result in the emergence of entrepreneurship (Young, 1961).

(3) Hagen also draws upon historical cases from Japan, Colombia, England and Russia, but more recent historical research leads one to question his conclusions. Wilken (1979) cites the studies of Fleming (1979), Yamamura (1974), Kaser (1978) and Gough (1969) proving that entrepreneurs need not necessarily come from groups that are seeking redress of social grievances (withdrawal of status respect). These studies found out that elite, upper class, upper 
middle class and even nobility were entrepreneurs in the above-mentioned areas, even if they were not socially disadvantaged.

Although Hagen's approach may be considered psychological, it takes into account social changes that this writer thinks is a breakthrough in the socio-cultural approach. It is one of the better approaches to explaining entrepreneurial behaviour because it views the process of how some societies 'unconsciously force' people into entrepreneurship. It does not just look at the struggle within the individual but considers the possible actions he can take to remedy his position in society.

\section{Social mobility}

Wilken (1979) refers to social structure as the existing structured patterns of interaction within a society. This social characteristic is regarded as significant for entrepreneurial emergence. This factor includes the degree of mobility, both social and geographical, and the nature of mobility channels within a situation.

He raises three points of views regarding this factor:

(1) A high degree of mobility is conducive to entrepreneurship. It is important that the system must be 'open' and 'flexible' in role relationships. All these imply the need for the possibility of mobility within a system, or for accessible mobility channels.

(2) Hagen (1968) strongly asserts that the lack of mobility possibilities promotes entrepreneurial behaviour. He refers to this as relative social blockage to indicate that only some channels of mobility must be blocked. Specifically, the mobility to non-entrepreneurial roles must be limited, while the possibility of upward by means of entrepreneurship is available to particular groups or individuals.

(3) The third position combines the first two - the need for both flexibility and the denial of conventional routes to prestige. Wilken (1979) simply notes that a setting should not be too rigid nor too flexible. If it is too flexible then individuals will gravitate toward other roles; if it is too rigid, entrepreneurship will be restricted along with other activities.
This writer agrees with Wilken that the patterning of mobility channels in a society are important in that they will determine the relative opportunities offered by entrepreneurial roles and other roles. But the degree and nature of social mobility within a society do not stand alone as influences upon entrepreneurship and that they will vary most likely in accordance with the legitimacy of entrepreneurship (the degree of approval or disapproval granted entrepreneurial behaviour), and the combined influence of both factors will relate significantly to the influence of marginality which is the next theory to be discussed .

\section{Micro level}

\section{Marginality}

Light (1979), claimed that disadvantages such as poverty, unemployment, underemployment, and discrimination in the labour force lead minority members to turn to selfemployment. He suggested that disadvantages in the job market push all minority members to turn to selfemployment but that those minority members with cultural resources successfully enter small business, while others without cultural resources find self-employment in petty trade (peddling), illegal enterprises, and predatory crimes. Light (1972) indicated in his research that the foreign born population has shown a higher proportion of selfemployment than the native born population because of its disadvantages in the labour market.

Wilken (1979:11) believes that the conditions under which marginality is likely to promote entrepreneurship are largely determined by the legitimacy of entrepreneurship and social mobility. Marginal individuals and groups will be excluded from access to the established mobility channels in a situation. Hence, marginals are likely to play entrepreneurial roles. In situations in which entrepreneurial legitimacy is low, 'mainstream' individuals will be attracted to nonentrepreneurial roles, and entrepreneurial roles will be relegated to marginals. But in instances when entrepreneurial legitimacy is high, mainstream individuals will use the entrepreneurial role as a mobility channel, and marginals will have to use other roles to be mobile.

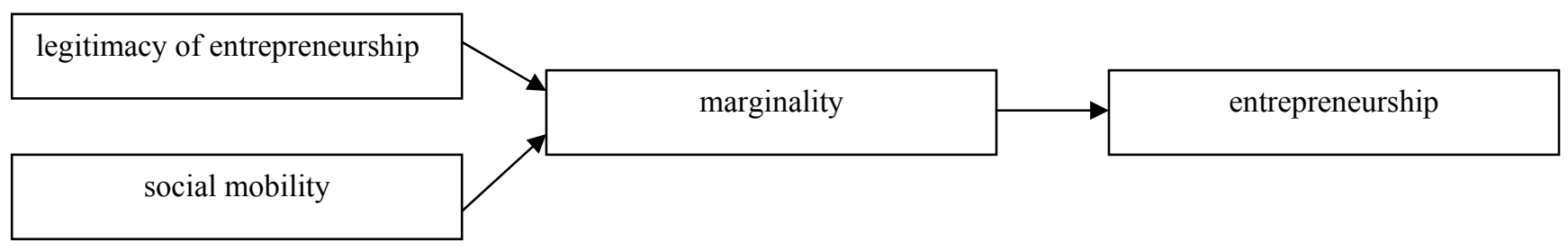

Figure 3: Diagram showing the relationship of marginality and entrepreneurship

Studies show that marginal entrepreneurship is more likely when entrepreneurship is not valid (Hoselitz, Kriesberg, Lipset as cited by Wilken, 1979:12). Since entrepreneurship is undesirable for 'unmarginalized' members of society, only marginals are 'forced' to it. Second, relative social blockage has also been emphasised as a condition promoting entrepreneurship by marginals (Kilby, 1971; Marris \& Somerset, 1971; \& McClelland, 1961). Since marginals do not have choices in terms of moving from one social stratum to another, or from one geographical area to another. 
Several other factors also are believed to increase the likelihood of marginals becoming entrepreneurs. One is the presence of positive attitudes toward entrepreneurship within the group (Hagen, 1962). Entrepreneurship must be accorded legitimacy within the group to compensate for the lack of legitimacy it faces outside the group. Entrepreneurship must be acceptable within the group in spite of its being unacceptable to society in general. The second important factor is a high degree of group solidarity or cohesion. This is necessary to counteract whatever opposition may be forthcoming from mainstream groups within the larger social situation. If an entire group of individuals in the society are under the same pressure, an individual in that group will find his values and behaviours around him confirmed in through the group. He will not be a deviant in the group. The group members reassure and protect each other in their new personalities. This in turn, according to Hagen (1962:246), greatly increases the prospect of effective innovation in technology of human relations.

This writer believes that marginality like other factors cannot be considered a sufficient condition for entrepreneurship. Not all marginal groups are entrepreneurial, (and not all entrepreneurial groups were marginal). Furthermore, marginals may be vulnerable to political attacks, which may negate their entrepreneurial efforts.

\section{Role models}

Another explanation that emphasises the influence of the environment on entrepreneurial behaviour - specifically the exposure of an individual to entrepreneurship or to entrepreneurs, is role theory.

Role theory (Pfeffer, 1982:98-99) argues that individuals in work organisations occupy positions. Associated with these positions (or jobs) are sets of activities, including interactions with others, that are required or expected as part of the job. This set of activities, including interactions, constitutes the role of the individual who occupies that position. Individuals in organisations are interdependent on each other, meaning, the performance of the individual's own role depends importantly on the activities of others in the role set, in turn the performance of others depends importantly on what the individual in the focal role does. Each has his or her own role expectations for appropriate behaviour. These behaviours get communicated to the role occupant and come to constitute role pressures. The occupant need not accurately perceive role pressures as sent or communicated by various members of the role set in the focal role. So whoever is the position occupant will receive the same demands and expectations as others. Whoever is the position occupant will have to learn that role.

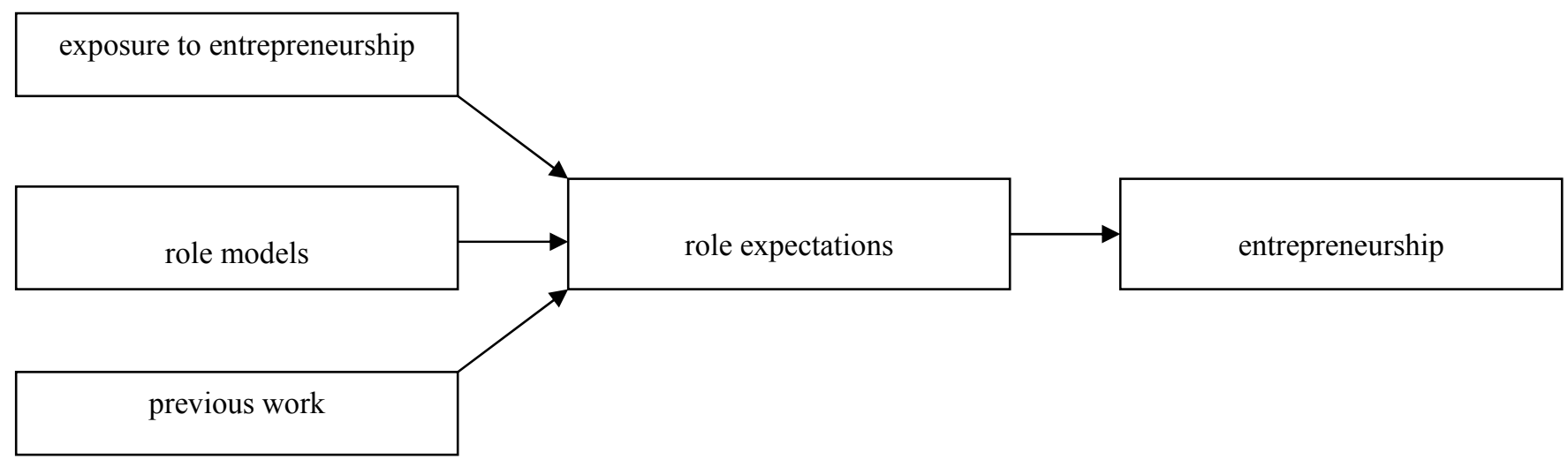

Figure 4: Diagram showing the relationship of role theory and entrepreneurship

The same is true with entrepreneurship. The more the entrepreneur fulfils role expectations, the more likely the individual will be to succeed in that venture (Carsrud \& Johnson, 1989). A number of researchers have reported that entrepreneurs have had previous experience in the industry in which they are starting their business. Prior work experience in the particular line of business is correlated positively with success (Vesper, 1982). Family and friends also seem to serve as role-models for aspiring entrepreneurs. Litvak and Maule (as cited by Shapero \& Sokol, 1982) found successful high-technology entrepreneurs had fathers who were owners-managers.

Shapero and Sokol (1982) both reported that the credibility of starting a new company appears to depend somewhat upon the entrepreneur's acquaintance with others who have started their own companies. Thus, an entrepreneur who starts an organisation may stimulate his employees to do the same, and employees who establish businesses encourage fellow employees to do likewise.

The literature also suggests that an unusually high percentage of entrepreneurs had fathers who were themselves entrepreneurs or farmers. (Roberts \& Wainer, 1971; Shapero, 1971; Susbauer, 1969; Collins \& Moore, 1970).

These findings seem to support the idea that seeing someone else succeed encourages prospective entrepreneurs to take the risk. In summary, the existence of a successful role model encourages entrepreneurial efforts. These models are often present in the work environment and encourage individuals to begin an entrepreneurial venture, especially when established work environment does not allow the 
employee room for creativity. In addition, the presence of strong family support is especially important to women and other minority entrepreneurs, who face problems when trying to begin a new small business. Also the higher the technological demands of the chosen industry, the more important it is that the entrepreneurs has had prior training and has worked with successful technological experts.

\section{A conceptual model of entrepreneurship}

The following conceptual model is constructed in an attempt to explain the entrepreneurship phenomenon using the theories that were discussed in this article. Based on the different theories presented, socio-cultural variables can be divided into four categories: culture, social changes, social structure and individual factors.

Cultural variables such as work attitudes, and the environment the individual is exposed to influences values. $\mathrm{He}$ assimilates these values and attitudes from family, friends, school, and to a certain extent church and religion (according to Weber). The exposure to culture that is supportive of entrepreneurship influences an individual to be one.

The results of the Global Entrepreneurship Monitor (2002) show that generally South African culture is still a negative factor towards Black entrepreneurship. The report stated that generations of discrimination and legal barriers to entrepreneurship among most of the South African population has resulted in a culture of dependency and more recently entitlement. This attitude has certainly reduced proactive efforts of individuals to take control of their own destinies and establishing their new firms. Most Black South Africans would rather wait when they get handed out 'what belongs to them', rather than work hard for something better.

The GEM report also mentions that the values inherent in groups living traditionally are not necessarily conducive to individual initiatives and entrepreneurship. It can further be argued that under apartheid rule, there evolved a strong antientrepreneurial culture specifically in Black communities, as a result of the political policy at that time (Allie \& Human, 1998:27).

The GEM report also indicated that preference for a job over self-employment is still strong in all sectors. Most Black South Africans would prefer the security of a full-time job than the uncertainty of generating income from running one's own business.

Various social changes as mentioned by Hagen result in withdrawal of status respect by a group or collectivity. This event thus results into psychological changes in individuals to react on this loss. One reaction to such loss is retreatism, which is characterised by psychological repression of trauma associated with the status loss. The suppressed rage resulting from the status loss ultimately results in a later lifting up of achievement standards that increases the likelihood of innovation and entrepreneurship.



Figure 5: Conceptual model of socio-cultural approach to entrepreneurship 
It is quite interesting to note that the Black South Africans were the majority when they were displaced during apartheid. The withdrawal of status respect from this event however did not result in retreatism, which normally precludes entrepreneurship. The Black South Africans instead reacted with ritualism - wherein lofty cultural goals were scaled down. The majority lived with the discrimination and adjusted their aspirations accordingly. Iheduru (1998) indicated that success for many Black South Africans involved adapting to apartheid by circumventing the law, living in the informal economy, or acquiring a powerful patron - a chief or a white person. Others found a niche in the formal economy as teachers, nurses or industrial workers.

Black South Africans gained their status respect back after apartheid but they have opted not to take the entrepreneurship route. A large number of Black South Africans are now successful in the private sector as lawyers, doctors and engineers, professions that were traditionally not options for them. In general, Black South Africans view professionals with more respect and admiration than they do entrepreneurs. A large number of Black South Africans have also embraced reformism by trying to help in the transformation of society and aiding in the institution of positive changes.

Social structure also influences the entrepreneurship event. In societies where entrepreneurship is not legitimate or accepted, individuals that are marginalised (that is, individuals that are excluded from access to the established social mobility channels) will likely play entrepreneurial roles.

In the case of South Africa, entrepreneurship during the apartheid was considered a legitimate and acceptable occupation and Black South Africans were deliberately inhibited from participating in it. Major laws such as Master and Servant Act (1911), Mines and Works Act (1911), Native's Land Act (1913), Native Urban Areas Act (1923), Group Areas Act (1950), Natives' Resettlement Act (1945), and Regulations Governing Black Business in Urban Areas (1962) were passed to impede Black South African who want to become entrepreneurs. It has been noted that there were more than 500 laws and regulations that in one way or the other impeded the involvement of the Black community in the economy as owners and managers (Motsuenyane, 1989).

According to Godsell (1991:92), another inhibition to Black entrepreneurship was the difficulty in obtaining business permits and the fact that one had to be "if not corrupt in an economic sense, then certainly politically corrupt and in cahoots with the white administrative bureaucracy of the township" in order to receive such services.

Additionally, Bank (1994:75-99) indicates that the Black entrepreneur in the township was probably the only businessman in South Africa to be the target of community and family contempt and hostility, especially by the youth, who defined him first as a businessman and second as a Black man. He was therefore a legitimate target of theft and attacks, along with white entrepreneurs, policemen and community councilors.

Lastly, individuals that have exposure to entrepreneurship as well as entrepreneurial role models will reinforce role expectations that are entrepreneurial. Role models communicate entrepreneurial behaviour. The lack of role models for Black entrepreneurs to emulate is evident in South Africa. There are more examples of successful politicians, lawyers and accountants than that of successful Black entrepreneurs. It is very difficult to encourage people to become entrepreneurs when they see few or even no concrete examples of others who have become successful in that career.

According to Bank (1994) few Black family businesses existed and survived. School graduates tended to join the industrial and civil service sector, where there were fewer raids and intimidation by the police and few if any attacks by the radical youth for collaborating with the 'system'. This is supported by Phillips and Brice (1988) who found that a socialist orientation is the basis of the Black community and as a result they are likely to exhibit behavioural patterns that are essentially co/operative or group focused. This is quite unlike the individualistic competitive patterns of the White community, which appears to have been adopted from its Western heritage. The implications of this are that Blacks have difficulty in associating with the free market system. This is highlighted and aggravated by examples identified by Clark and Masinga (1986) where 'conmen' have targeted Black entrepreneurs leading to disillusioned, bitter and disinterested potential entrepreneurs.

\section{Conclusions and research recommendations}

This paper has discussed five main socio-cultural theories namely: Weber's Protestant ethic, Hagen's withdrawal of status, social mobility, marginality and role models. The socio-cultural approach takes into account differences among societies and cultures in explaining entrepreneurial activity. The case of Black South African entrepreneurs was used to illustrate how the different theories can explain the lack of entrepreneurship in this ethnic group.

Based on the criticism given to the different theories, it is evident that the major problem with the socio-cultural approach is that the groups alleged to possess a propensity to entrepreneurship display their predisposition only under limited, country-specific and historically specific conditions. Prior to immigration, persons originating from alleged entrepreneurial cultures are mostly indistinguishable from others around them, but in their new surroundings they take on entrepreneurial characteristics. Research findings strongly suggest that the flowering of a group's predisposition to entrepreneurship to situational rather than deterministic conditions.

Although these socio-cultural theories explain the emergence of entrepreneurial activity, not one can be used as the 'one' absolute answer. Economic and psychological factors must still be taken into consideration in order to come up with a holistic explanation of this phenomenon. 
Models such as that of Shapero and Sokol (1982) which suggest that entrepreneurial formations are the result of interacting situational and cultural factors are more useful in explaining entrepreneurship among ethnic subgroups.

Based on the literature survey, the following some possible areas for research are suggested:

(1) examine culture and values and their influence on entrepreneurial activity (as motivators and deterrents)

(2) conduct comparative research (across regions or countries) to validate existing studies or theories linking socio-cultural variables to firm formation and performance;

(3) determine what social and cultural restructuring should be done in order to promote entrepreneurial activity;

(4) explore how entrepreneurs interpret and evaluate the socio-cultural environment in deciding on firm formation, what information they use, how they obtain them;

(5) investigate the effect of government policy on sociocultural variables that encourage or hinder entrepreneurial activities

(6) develop contingency models that specify various leader qualities effective given certain contingencies (Carsrud \& Johnson, 1989);

(7) develop transactional models of leadership to account for the role of the social environment in the relationship of entrepreneurs and other individuals (Carsrud \& Johnson, 1989), and

(8) conduct correlational studies linking relationships between socio-cultural variables in order to come up with a theoretical framework that can clearly explain entrepreneurial activity.

\section{References}

Allie, F. \& Human, L. 1998. 'Africa: South'. In Morrison, A. (Ed.). Entrepreneurship: An international perspective. Oxford: Butterworths.

Bank, L. 1994. 'Between traders and tribalists: Implosion and the politics of disjuncture in a South African homeland', African Affairs, 93(370):75-99.

Begley, T., Tan, W.L., Larasati, A., Rab, A., Zamora, A. \& G. Nanayakkara. 1997. The relationship between sociocultural dimension and interest in starting a business: A multi-country study. Frontiers of Entrepreneurship Research. Wellesley, MA: Babson College.

Carsrud, A. \& Johnson, W. 1989. 'Entrepreneurship: A social psychological perspective', Entrepreneurship and Regional Development, 1(1):21-32.
Clark, I. \& Masinga, J. 1986. 'Black business: today and tomorrow'. In Energos, South Africa, change and chaos. Sandton: Aviation Publications.

Collins, O.F. \& Moore, D.G. 1970. The organisational makers: A behavioural study of independent entrepreneurs. New York: Meredith.

Fleming, W.J. 1979. 'The cultural determinants of entrepreneurship and economic development: A case study of Mendoza Province, 1861-1914', Journal of Economic History, 39:211.

Global Entrepreneurship Monitor. 2002. 'South Africa 2002 GEM National Report.' [online] http://www.gemconsortium.org/download.asp?fid=283.

Godsell, G. 1991. 'The social networks of South African entrepreneurs'. Unpublished Ph.D. thesis. Boston: Boston University Graduate School.

Gough. J.W. 1969. The rise of the entrepreneur. New York: Schocher Books.

Hagen, E. 1968. The economics of development. Illinois: Dorsey Press.

Hagen, E. 1962. On the theory of social change. Illinois: Dorsey Press.

Iheduru, O.C. 1998. 'Black entrepreneurs in post-Apartheid South Africa'. In Spring, A. \& McDade, B. E. (Eds.). African entrepreneurship. Theory and reality. Gainesville: University of Florida Press.

Kaser, M.C. 1978. 'Russian entrepreneurship'. In The Cambridge Economic History of Europe VII, Part 2. London: Cambridge University.

Kilby, P. 1971. 'Hunting the heffalump'. In Kilby, P. (Ed.). Entrepreneurship and economic development. New York: Free Press pp.11-40.

Light, I. 1979. 'Disadvantaged minorities in selfemployment', International Journal of Comparative Sociology, 20:31-45.

Light, I. 1972. Ethnic enterprise in America: Business and welfare among Chinese, Japanese and Blacks. Berkeley: University of California Press.

Marris, P. \& Sommerset, A. 1971. The African entrepreneur: A study of entrepreneurship and development in Kenya. New York: Africana.

McClelland, D. 1961. The achieving society. New York: Free Press.

McGrath, R. \& Macmillan, I. 1991. More like each other? A cross cultural study of entrepreneurial perceptions. Frontiers of Entrepreneurship Research. Wellesley, MA: Babson College. 
Motsueyane, A. 1989. The development of black entrepreneurship in South Africa. Lagos: Nigerian Institute of International Affairs.

Phillips, B. \& Brice, H. 1988. 'Black business in South Africa: A challenge to enterprise', International Journal of Small Business, 6(3):42-58.

Pfeffer, J. 1982. Organisations and organisation theory. London: Pitman.

Roberts, E.B. \& Wainer, W.A. 1971. 'Some characteristics of technical entrepreneurs', IEEE Transactions on Engineering Management, 18:36.

Shapero, A. 1971. An action program of entrepreneurship. Austin: Multi-Disciplinary Research.

Shapero, A. \& Sokol, L. 1982. 'The social dimension of entrepreneurship'. In Kent, C.A., Sexton, D.L. \& Vesper, K.H. (Eds.). Encyclopaedia of entrepreneurship. Englewood Cliffs: Prentice-Hall.

Susbauer, J.C. 1969. 'The technical company formation process: A particular aspect of entrepreneurship'. Doctoral dissertation. Austin; University of Texas.

Vesper, K. 1982. 'Introduction and summary of entrepreneurship research.' In Kent, C.A., Sexton, D.L. \& Vesper, K.H. (Eds.). Encyclopaedia of Entrepreneurship. Englewood Cliffs: Prentice-Hall.

Weber, M. 1958. The Protestant ethic and the spirit of capitalism. New York: Scribner's Publishing.

Wilken, P. 1979. Entrepreneurship: A comparative and historical study. New Hersey: Ablex Publishing Corporation.

Yamamura, K. 1974. A study of samurai income and entrepreneurship. Cambridge: Harvard University Press.

Young, F. 1961. A macrosociological interpretation of entrepreneurship. Entrepreneurship and economic development. New York: Holt, Rinehart, Winston. 
